Europe's Journal of Psychology, 6(3), pp. 196-212

www.ejop.org

\title{
Humor Creation Ability and Mental Health: Are Funny People more Psychologically Healthy?
}

\author{
Kim R. Edwards \\ Univ ersity of Western Ontario
}

Rod A. Martin

University of Western Ontario

\begin{abstract}
Sense of humor is a multidimensional personality construct. Some components may be more relevant to psychological health than others. While there has been a considerable amount of research on humor styles, humor creation ability (HCA) has remained relatively understudied in relation to well-being. This study employed two methods of assessing HCA (a cartoon captioning task and a task involving the generation of humorous responses to vignettes depicting everyday frustrating situations) to study associations with mental health variables. In addition to these humor creation performance tasks, 215 participants completed measures of four humor styles (Humor Styles Questionnaire) and psychological well-being (self-esteem, satisfaction with life, optimism, depression, anxiety, and stress). No significant correlations were found between either of the HCA tasks and any of the well-being measures. In contrast, humor styles were significantly correlated with well-being variables in ways consistent with previous research. In addition, the frustrating situation humor creation task was positively correlated with all four humor styles. These findings add support to the view that the ability to create humor is less relevant to mental health than are the ways people use humor in their daily lives. Implications for humor-based interventions are discussed.
\end{abstract}

Key Words: humor creation ability, humor styles, well-being, mental health.

The notion that a sense of humor is beneficial for mental health has been popularized by clinicians, personality theorists, and researchers for decades. Indeed, a considerable amount of research evidence has accumulated, showing positive 
correlations between various measures of sense of humor and many aspects of psychosocial well-being (e.g., life satisfaction, self esteem). Negative correlations have also been found with measures of depression, anxiety, stress, burnout, and so on (for a review of this literature, see Martin, 2007). It is important to recognize, however, that sense of humor is a multifaceted personality construct, and researchers need to identify which aspects or components of this trait are most relev ant to mental health. For example, sense of humor can be conceptualized as a habitual behavior pattern (e.g., tendency to tell jokes and amuse others, tendency to laugh frequently), an attitude (enjoyment of humor), a coping strategy (use of humor to cope with stress), an aesthetic response (enjoyment of particular forms of humor), or an ability (ability to create humor). These different components of sense of humor are not all highly correlated with each other (e.g., Köhler \& Ruch, 1996), and some of them may be more relevant to psychological health and well-being than others.

This is particularly relevant for clinicians who may be interested in developing humorbased interventions designed to enhance their clients' psychological health, wellbeing, and quality of life (e.g., McGhee, 1999). Research examining associations between different components of sense of humor and well-being could be useful for identifying which aspects of humor should be targeted in these sorts of interventions. Should such programs focus, for example, on exposing clients to comedy videos and other humorous materials, on teaching them to laugh vigorously even in the absence of humorous stimuli, on training them to improve their humor creation skills, or on encouraging them to seek humor in their daily lives and share it with their friends? If any of these specific aspects of humor are found to be unrelated to wellbeing variables, this would suggest that there is not likely to be much benefit in including them in humor-based interventions.

In most of the correlational research on humor and well-being in recent decades, sense of humor has been measured by means of self-report scales assessing the degree to which individuals tend to engage in a variety of humor-related activities in their daily lives. For example, various humor measures used in past research have assessed the degree to which individuals tend to notice and enjoy humor (Sense of Humor Questionnaire; Svebak, 1974), laugh frequently in a variety of situations (Situational Humor Response Questionnaire; Martin \& Lefcourt, 1984), and use humor to cope with stressful life events (Coping Humor Scale; Martin \& Lefcourt, 1983). In recent years, much of the research on humor and well-being has employed the Humor Styles Questionnaire (HSQ; Martin et al., 2003), which assesses four different humor styles, or ways in which people may use humor in their daily lives. This measure distinguishes between two potentially beneficial uses of humor (affiliative 
and self-enhancing) and two potentially detrimental uses (aggressive and selfdefeating). A considerable amount of correlational research has provided evidence that these humor styles are differentially associated with measures of emotion wellbeing and social adjustment (Martin, 2007; Martin, et al., 2003).

However, one aspect of sense of humor that has received very little research attention in relation to psychological well-being is humor creation ability (HCA). HCA is an ability-related trait which has to do with how skilled or competent a person is at producing humorous or witty verbal responses that most people would perceive as funny. This is in contrast to most self-report humor measures, which view humor as a typical or habitual behavior pattern, assessing how frequently the person tends to enjoy humor, amuse others, laugh, use humor to cope with stress, and so on. As such, HCA is most appropriately assessed using maximal performance tests, in a manner similar to tests of intelligence or creativity, rather than self-report scales, which are more appropriate for assessing typical performance. In previous studies, researchers have measured HCA by asking participants to create funny captions for captionless cartoons (e.g., Babad, 1974; Köhler \& Ruch, 1996), witty narratives for films (Lefcourt \& Martin, 1986), humorous descriptions of miscellaneous objects (Lefcourt \& Martin, 1986; Turner, 1980), or funny presidential campaign slogans (Clabby, 1980). Funniness ratings of these humorous productions are used as measures of the participants' humor creation ability.

One would expect that individuals with high scores on self-report humor measures, such as the subscales of the HSQ, would tend to have a good ability to create humor, resulting in some degree of positive correlation between the two types of measures. Nonetheless, these two aspects of sense of humor are not necessarily highly correlated. For example, some people frequently make others laugh by telling memorized jokes or often enjoy laughing at other people's jokes, without having a high level of ability to create humor themselves. Others may be very skilled at creating highly original jokes and witty responses when asked to do so, but may not tend to use humor very much when confronted with stressful life situations or engage in much witty banter in their daily interactions with others. Indeed, in past research examining associations between HCA and various self-report humor measures, correlations have typically been in the non-significant to moderate range (e.g., Köhler \& Ruch, 1996; Lefcourt \& Martin, 1986). No previous studies have examined correlations between HCA and the subscales of the Humor Styles Questionnaire.

Like other forms of creativity, humor creation ability requires divergent thinking, flexibility, and the ability to generate multiple novel ideas in response to a given stimulus (O'Quin \& Derks, 1997). In a review of studies exploring the association 
between HCA and various tests of general creativity, O'Quin and Derks (1997) found an average correlation of .34. They concluded that, although creativity and HCA inv olve similar mental processes, they should be considered distinct abilities. Whereas humor productions are typically creative, individuals can be creative without being humorous.

How might HCA be potentially beneficial for psychological well-being? One can speculate that the ability to think flexibly and adopt multiple perspectives simultaneously, which seems to be important for humor creation, might also be a useful coping skill for reappraising potentially stressful situations as less threatening and overwhelming, resulting in less adverse physiological and emotional consequences (Lazarus \& Folkman, 1984; Martin \& Lefcourt, 1983). This hypothesis assumes that people who are skilled at creating humor do, in fact, use this ability in their everyday lives. It is possible, however, that an individual who is able to be very funny on a performance test of humor creation does not tend to use humor to cope when faced with an actual stressful situation. In that case, humor creation ability may be only weakly related, or even unrelated, to well-being.

Past research examining the relationship between HCA and psychological wellbeing has been sparse. Martin and Lefcourt (1983) found support for a stressmoderating role of HCA (measured via humorous narratives generated in response to a stressful film and funny descriptions of miscellaneous objects), indicating that individuals with higher HCA experienced a weaker relationship between stress and mood disturbance than did those with less ability to generate humor. However, this study found no simple direct correlations between HCA and well-being measures. Clabby (1980) found that HCA (measured with several humor-generation tasks) was positively correlated with a measure of personal adjustment (positive outlook on life, flexibility in demeanor, and the capacity to get along well with others). Finally, although not directly related to mental health, Masten (1986) noted that children who scored higher on measures of humor production (assessed using the cartoon caption task) paid more attention to instructions, displayed greater cooperation, and were considered more cheerful by friends.

In view of the very limited and somewhat contradictory findings of past studies, further research in this area seems to be needed. Accordingly, the first objective of the present study was to investigate further the possible relationship between HCA and various aspects of psychological well-being. We assessed well-being by means of self-report measures of self-esteem, optimism, satisfaction with life, depression, anxiety, and stress. We employed two different performance tasks for assessing HCA. The first of these involved asking participants to generate humorous captions for 
captionless cartoons, the most widely-used technique in previous research on HCA. The second measure was developed specifically for this study. In this task, participants were presented with brief descriptions of several potentially frustrating, embarrassing, or upsetting situations that could commonly occur in people's lives. They were instructed to imagine that they had experienced each situation, and then to create a funny description of the experience that they might later relate to a good friend. For both tasks, the participants' humor creations were subsequently rated for funniness by several research assistants to obtain mean humor creation ability scores. We speculated that the second task might be especially useful for assessing aspects of humor creation ability that are particularly relevant to coping with stress. We therefore expected that funniness scores from this task would be more strongly associated with measures of psychological well-being than would scores from the cartoon captioning task.

We also included the Humor Styles Questionnaire in this study, to compare the correlations between the HCA measures and psychological well-being variables with those obtained between humor styles and well-being. Past research has generally shown that affiliative and self-enhancing humor tend to be positively correlated with psychosocial well-being, whereas aggressive and self-defeating humor are generally negatively associated with various well-being variables (Martin, 2007; Martin et al., 2003), and we expected to replicate these patterns in the present study.

The second objective of this study was to examine the possible relationships between the four humor styles and the two measures of humor creation ability. Because all four of the humor styles are assumed to involve the ability to generate humor and amuse others (albeit for different purposes), we expected that each of the subscales of the HSQ would be positively correlated with the two HCA measures.

\section{Method}

Participants

The sample was comprised of 215 first-year undergraduate students (92 males, 123 females) enrolled in an Introductory Psychology course at the University of Western Ontario. Participants were recruited through the department research participant pool and were compensated with partial course credit. The mean age of participants was 18.58 years $(S D=1.99)$. With regard to ethnicity, $71.6 \%$ identified themselves as being of European origin, 14\% Asian, 4.7\% South Asian, 3.3\% African/Caribbean, $0.5 \%$ Native Canadian, and $5.1 \%$ other. Eighty-one percent of 
participants were born in Canada and $81.9 \%$ indicated that English was their first language.

Measures

Demographic Questionnaire

A brief demographic questionnaire was administered to provide general information about participants' age, gender, ethnicity, country of birth, and first language.

\section{Cartoon Caption Task (CCT)}

The CCT required participants to generate as many funny captions as possible in response to five captionless cartoons in a period of 10 minutes. The cartoons were selected from The New Yorker (2008) c artoon caption contest website. Six volunteer student research assistants (two male and four female) coded the funniness of each caption attempt on a 4-point Likert-type scale ranging from 1 (no incongruity or attempts to be witty/funny) to 4 (extremely humorous attempts, coupled with creativity, plenty of incongruity and very original humor). The mean rating score, averaged across the 6 raters and all the responses of each participant, was used as the measure of humor creation ability in subsequent analyses (Köhler \& Ruch, 1996). Inter-rater reliability (internal consistency) was calculated using the ratings of each of the six raters, averaging across all the responses of each participant, as equiv alent to six items on a scale. Overall reliability (coefficient alpha) among co ders was .79.

\section{Frustrating Situation Humor Creation Task (FSHCT)}

The FSHCT is comprised of short descriptions of five potentially frustrating situations, each accompanied by a line drawing depicting the situation. An example is "After spending the day shopping and running errands, you come out of the busy mall and can't remember where you parked your car." Participants were instructed to imagine that the frustrating situation had happened to them and then to consider how they would later recount the experience to a friend in as funny a way as possible. They were given 15 minutes to record as many funny statements as they could, pertaining to their feelings, reactions, or description of the situation. These responses were then rated for wittiness by the same six raters who rated the CCT. Like the CCT, the mean wittiness rating on the FSHCT provides a measure of humor creation ability. Inter-rater reliability for the FSHCT, which was calculated in the same way as for the CCT, was .80.

Humor Styles Questionnaire (HSQ; Martin et al., 2003).

The HSQ examines four dimensions corresponding to individual differences in the spontaneous experience and expression of humor in everyday life. Self-enhancing 
humor (e.g., "If I am depressed I can usually cheer myself up with humor") and Affiliative humor (e.g., "I laugh and joke a lot with my friends") are the two adaptive styles. Aggressive humor (e.g., "If I don't like someone, I often use humor or te asing to put them down") and Self-defeating humor (e.g., "I let people laugh at me or make fun at my expense more than I should") are the potentially detrimental styles. The $\mathrm{HSQ}$ consists of 32 items (eight for each scale) rated on a 7-point, Likert-type scale ranging from 1 (totally disagree) to 7 (totally agree). Past research has de monstrated that the HSQ is a reliable and valid measure (e.g., Chen \& Martin, 2007; Kuiper, Grims haw, Leite, \& Kirsh, 2004; Martin, 2007; Martin et al., 2003). In the present study, internal consistencies (Cronbach's alpha) for the Afilliative, Self-enhancing, Aggressive and Self-defeating scales were .81, .84, .73, and .79, respectively.

Depression, Anxiety, Stress Scales (DASS; Lovibond \& Lovibond, 1995).

The DASS is a 42-item measure consisting of three self-report scales which measure the negative emotional states of depression (e.g., "I couldn't seem to experience any positive feelings at all"), anxiety ("I was aware of dryness of my mouth") and stress ("I found myself getting upset by quite trivial things"). Participants indicate how much a given statement has applied to them over the past week, using a 4-point Likert-type scale ranging from 1 (did not apply to me at all) to 4 (applied to me very much, or most of the time). Previous research has demonstrated that the DASS has psychometrically acceptable levels of reliability and validity (e.g., Lovibond \& Lovibond; Nieuwenhuijsen, de Boer, Verbeek, Blonk, \& van Dijk, 2003). The internal consistencies (Cronbach's alphas) of Depression, Anxiety and Stress in this study were $.94, .89$, and .91 , respectively.

Life Orientation Test - Revised (LOT-R; Scheier \& Carver, 1985).

The LOT-R assesses individual differences in optimism. This self-report scale consists of six statements plus four filler items. An example item is, "In uncertain times, I usually expect the best." Respondents indicate the degree to which each statement is consistent with their own feelings on a 5-point Likert-type scale ranging from 0 (strongly disagree) to 4 (strongly agree). A higher total score indicates a greater degree of optimism. Previous research with the LOT-R has demonstrated good reliability and validity (e.g., Scheier, Carver \& Bridges, 1994). The internal consistency (Cronbach's alpha) of the LOT-R in the current study was .73.

Rosenberg Self-Esteem Scale (RSE; Rosenberg, 1965).

The RSE is a widely used unidimensional measure of global self-esteem that consists of 10 items. Participants rate statements describing general feelings of self-worth and self-acceptance on a 4-point Likert-type scale ranging from 1 (strongly agree) to 4 (strongly disagree). An example item is, "I feel that I have a number of good 
qualities." Half the scale items are reverse coded. Previous research has demonstrated good reliability and validity (e.g., Silbert \& Tippett, 1965). The internal consistency in this study was .86 .

Satisfaction with Life Scale (SLS; Diener, Emmons, Larsen, \& Griffin, 1985).

The SLS includes five statements which assess overall cognitive judgments regarding life satisfaction. Participants rate each statement using a 7-point Likert-type scale ranging from 1 (strongly disagree) to 7 (strongly agree). An example item is, "The conditions of my life are excellent." The SLS has demonstrated good reliability and convergent validity with other well-being measures (Diener et al.). The internal consistency in this study was .85 .

\section{Procedure}

Participants were tested in groups of 10 to 20. After completing informed consent, they were given the CCT followed by the FSHCT. A package of self-report questionnaires was then administered to participants in a randomized order. Completion of the tasks and measures took approximately one hour, after which participants received a debriefing form describing the purpose of the study.

\section{Results}

Table 1 presents the means and standard deviations of all the measures used in this study as well as the t-tests of differences between males and females on each of the questionnaires. The only significant gender difference for the humor measures occurred with the Aggressive humor subscale of the HSQ, on which males obtained significantly higher mean scores than females $(t(213)=3.31, p<.01)$. Interestingly, no differences were found between males and females on the two humor creation tasks, indicating that men and women did not differ in their ability to generate humorous responses. A number of gender differences were also apparent on the mental health variables. In particular, females reported significantly lower optimism and self-esteem (both ps <.05), and significantly higher ratings of anxiety and stress (ps <.01) in comparison to males. Because of these gender differences, the subsequent analyses made use of partial correlations, controlling for sex.

With regard to our first objective, Table 2 displays the Pearson partial correlations between the humor measures (CCT, FSHCT, HSQ) and psychological well-being measures, controlling for sex. As seen in this table, none of the scores on the two HCA tasks were significantly correlated with scores on any of the well-being measures. In 
Table 1: Means and Standard Deviations for All Measures and t-test Results Comparing Males and Females on these Measures

\begin{tabular}{|c|c|c|c|c|c|c|c|}
\hline & \multicolumn{2}{|c|}{ Total Sample } & \multicolumn{2}{|c|}{ Males } & \multicolumn{2}{|c|}{ Females } & \multirow[b]{2}{*}{$t$-test } \\
\hline & Mean & SD & Mean & SD & Mean & SD & \\
\hline Cartoon Caption Task & 2.04 & .33 & 2.09 & 0.36 & 2.01 & 0.30 & $\overline{n s}$ \\
\hline \multicolumn{8}{|l|}{ Frustrating Situation } \\
\hline Humor Creation Task & 2.12 & .39 & 2.17 & 0.44 & 2.09 & 0.34 & ns \\
\hline Affiliative Humor & 47.62 & 6.05 & 48.26 & 5.90 & 47.14 & 6.14 & ns \\
\hline Self-Enhancing Humor & 38.30 & 8.43 & 38.33 & 8.18 & 38.27 & 8.64 & ns \\
\hline Aggressive Humor & 31.54 & 7.92 & 33.57 & 7.81 & 30.03 & 7.68 & $3.31^{* *}$ \\
\hline Self-Defeating Humor & 28.96 & 8.64 & 29.29 & 8.63 & 28.72 & 8.67 & ns \\
\hline Depression & 6.59 & 7.59 & 5.89 & 7.07 & 7.11 & 7.94 & ns \\
\hline Anxiety & 7.06 & 7.22 & 5.58 & 5.99 & 8.16 & 7.87 & $-2.63^{* *}$ \\
\hline Stress & 11.16 & 8.14 & 9.18 & 6.99 & 12.64 & 8.64 & $-3.15^{* *}$ \\
\hline Optimism & 22.31 & 4.86 & 15.13 & 4.32 & 13.88 & 3.89 & $2.23^{*}$ \\
\hline Self-esteem & 14.41 & 4.11 & 23.22 & 5.02 & 21.63 & 4.64 & $2.39^{*}$ \\
\hline Satisfaction with life & 25.82 & 5.52 & 25.79 & 5.78 & 25.84 & 5.34 & ns \\
\hline
\end{tabular}

$* p<.05, * * p<.01$

Table 2: Partial Correlations between Mental Health Variables and Scores on the HSQ and Humor Creation Tasks (Controlling for Sex)

\begin{tabular}{|c|c|c|c|c|c|c|c|}
\hline & & \multicolumn{6}{|c|}{ Mental Health Variables } \\
\hline & & \multirow[b]{2}{*}{ Dep. } & \multirow[b]{2}{*}{ Anxiety } & \multicolumn{3}{|c|}{ Self- } & \multirow{2}{*}{$\begin{array}{c}\text { Sat. w/ } \\
\text { Life }\end{array}$} \\
\hline & & & & Stress & Esteem & Optim. & \\
\hline \multirow[t]{4}{*}{$\overline{H S Q}$} & $\mathrm{AF}$ & $-.14^{*}$ & $-.14^{*}$ & $-.19^{* *}$ & .05 & .03 & .10 \\
\hline & SE & $-.25^{* * *}$ & $-.19 * *$ & $-.23 * * *$ & $.27^{* * *}$ & $.26^{* * *}$ & $.26^{* * *}$ \\
\hline & $A G$ & $.19 * *$ & $.18^{* *}$ & $.25^{* * *}$ & $-.20 * *$ & $-.25^{* * *}$ & -.12 \\
\hline & SD & $.14^{*}$ & $.15^{*}$ & .13 & $-.31^{* * *}$ & $-.16^{*}$ & -.03 \\
\hline ССТ & & .08 & -.05 & .00 & -.03 & -.03 & -.06 \\
\hline FSHCT & & .00 & -.07 & -.09 & .08 & .08 & .12 \\
\hline
\end{tabular}

Note. $\mathrm{HSQ}=$ Humor Styles Questionnaire, $\mathrm{AF}=$ affiliative humor, $\mathrm{SE}=$ self-enhancing humor, $A G$ = aggressive humor,$S D=$ self-defeating, $C C T=$ Cartoon Captioning Task, FSHCT $=$ Frustrating Situation Humor Creation Task, Dep. $=$ depression, Optim. $=$ Optimism, Sat. $w /$ life = satisfaction with life

${ }^{*} p<.05,{ }^{* *} p<.01{ }^{* * *} p<.001$ 
contrast, a number of significant correlations were found with the scales of the HSQ. In particular, the two adaptive humor styles, Self-enhancing (SE) and Affiliative (AF) humor, demonstrated significant negative correlations with depression, anxiety, and stress (partial $r$ range $=-.14$ to -.25 ). Additionally SE humor displayed significant positive correlations with self-esteem, optimism, and satisfaction with life (mean partial $r=.26$, all ps <.001). Both aggressive (AG) and self-defeating (SD) humor, the two potentially detrimental styles, were positively correlated with depression and anxiety (partial $r$ range $=.14$ to .19, all ps <.05), as well as negatively correlated with self-esteem and optimism (partial $r$ range $=-.16$ to -.31 , all $p s<.05$ ). AG was also positively correlated with stress (partial $r=.25, p<.001$ ).

Table 3: Correlations between the subscales of the HSQ and the CCT and FSHCT

\begin{tabular}{|c|c|c|c|c|c|c|}
\hline \multirow{2}{*}{$\begin{array}{l}\text { Note. HSQ } \\
\text { Styles }\end{array}$} & & \multicolumn{2}{|r|}{$\overline{H S Q}$} & \multirow{2}{*}{$\begin{array}{c}\mathrm{HSQ} \\
\mathrm{SE}\end{array}$} & \multirow{2}{*}{$\begin{array}{c}\mathrm{HSQ} \\
\mathrm{AG}\end{array}$} & \multirow{2}{*}{$\begin{array}{c}\mathrm{HSQ} \\
\mathrm{SD}\end{array}$} \\
\hline & & $\mathrm{CCT}$ & $A F$ & & & \\
\hline & CCT & - & .05 & .08 & .08 & .08 \\
\hline & FSHCT & $.37^{* * *}$ & $.27^{* * *}$ & $.28^{* * *}$ & $.16^{*}$ & $.17^{*}$ \\
\hline
\end{tabular}

Questionnaire, AF = Affiliative humor, $S E=$ self-enhancing humor, $A G=$ aggressive humor, SD = self-defe ating humor, CCT = Cartoon Captioning Task, FSHCT = Frustrating Situation Humor Creation Task

$* p<.05, * * * p<.001$

With regard to the second main objective of this study, the results shown in Table 3 reveal that the CCT was not significantly correlated with any of the subscales of the HSQ. However, the FSHCT was significantly positively correlated with all four humor styles (mean $r=.22$, range $=.16$ to .27 , $p s<.05$ ). As seen in the table, the correlations with the two adaptive humor styles appear to be stronger than those with the two maladaptive humor styles. We therefore conducted two hierarchical regression analyses to determine whether affiliative and self-enhancing humor each added significantly to the prediction of FSHCT after controlling for aggressive and selfdefeating humor. After entering aggressive and self-defeating humor, affiliative humor remained a significant predictor of FSHCT scores $(F$ change $(1,211)=11.92, p$ $\left.=.001,) \mathrm{R}^{2}=.05\right)$, as did self-enhancing humor $(F$ change $(1,211)=13.81, p<.001,) \mathrm{R}^{2}$ $=.06)$. In addition, scores on the CCT were positiv ely correlated with scores on the FSHCT $(r=.37, p<.001)$, indic ating that the two methods of assessing humor creation ability are moderately correlated. 


\section{Discussion}

This study had two main objectives. The first of these was to explore the potential links between humor creation ability (HCA) and several measures of psychological well-being, including optimism, self-esteem, satisfaction with life, de pression, anxiety, and stress. HCA was measured using two performance tasks to explore the possibility that the ability to generate humorous comments in response to everyday frustrating situations (measured using the FSHCT) is more strongly correlated with mental health variables than is the ability to create funny captions for cartoons (measured with the CCT).

The results indicated that neither the CCT nor the FSHCT was significantly correlated with any of the psychologic al health measures, suggesting that the ability to create humor (either in response to frustrating situations or in cartoon captions) is not associated with well-being. A possible explanation for this finding is that individuals who have the ability to create humor do not necessarily use this ability in their daily lives in health-enhancing ways (such as in times of stress, interpersonal tension, etc.). It is also possible that humor creation ability may be correlated with other well-being variables that were not explored in the present study. For example, whereas the present study focused on internalizing problems such as anxiety and depression, it is possible that HCA is associated with externalizing behaviors (such as hostility or aggression). In support of this possibility, previous research has demonstrated that HCA is positively correlated with extraversion (Köhler \& Ruch, 1996; Koppel \& Sechrest, 1970), and other studies have found that extraverted individuals are more likely to have externalizing than internalizing disorders (Shiner, 2006). Therefore, although persons who are skillful at creating humor may be no more or less psychologic ally healthy than the average individual (as suggested by the results of this study), when such individuals do experience mental health problems, they may be more prone to externalizing than internalizing ones. Future research could explore these hypotheses.

Given the notion that humor is a multidimensional concept, some humor facets may be related to psychological health and well-being, whereas others, such as humor creation ability, appear unrelated. As Martin (2008) noted, different humor dimensions are not all highly correlated with each other, and as a result, researchers must undertake the challenge of identifying which components are relevant for wellbeing. Replicating the results of previous research (Martin et al., 2003), our findings pertaining to the HSQ indicate that the hypothesized beneficial humor styles (and particularly self-enhancing humor) correlate negatively with depression, anxiety, and 
stress, and positively with self-esteem, optimism, and satisfaction with life. On the other hand, the potentially detrimental humor styles correlated positiv ely with anxiety and depression and negatively with self-esteem and optimism. These findings support the importance of distinguishing between positive and negative uses of humor in mental health. Psychological health involves not only the presence of adaptive uses of humor, but also the absence of negative or unhealthy styles (Martin et al). Moreover, taken together with the lack of correlations found with the HCA measures, these findings suggest that the ways in which humor creation is used in daily life are more important for well-being than is simply the ability to create humor.

The second major objective of this study was to explore the relationships between humor styles and humor creation ability. We expected that individuals with higher scores on each of the humor styles would be better able to create humor which other people find funny. In support of this prediction, humor creation ability, assessed by the FSHCT, was significantly and positively correlated with all four humor styles. This finding provides further validation for the HSQ, indic ating that individuals with high scores on each of the four humor styles tend to be skilled at creating humor, regardless of whether they use their humor in beneficial or deleterious ways.

Moreover, this finding provides additional support for the notion that humor creation ability, by itself, is not necessarily advantageous for mental health. Some persons have the ability to be very funny but use their humor in detrimental (e.g., aggressive or self-defeating) rather than beneficial ways (e.g., affiliative or self-enhancing). Consequently, the manner in which individuals use humor in their daily lives is more important to mental health than how funny they are able to be.

While all four humor styles were positiv ely correlated with the FSHCT, the associations with the positive humor styles were significantly higher than those with the negative styles. One possible explanation for this finding is that the frustrating situation task taps into the adaptive more than the maladaptive humor styles. When asked to create humorous responses that they would share with a friend during times of stress or frustration, participants may be more likely to produce affiliative (i.e., friendly) and self-enhancing (i.e., coping) styles of humor, rather than aggressive or self-defeating. An alternative possible explanation is that humor creation attempts incorporating aggressive or self-defeating humor are simply not as funny as those responses which involve more beneficial styles of humor, resulting in lower funniness ratings by our raters and consequently weaker correlations. In future research using these HCA measures, it would be interesting to code responses according to the four humor styles, to determine whether some styles are used more frequently than others and whether certain styles are considered funnier than others. 
In contrast to the findings with the FSHCT, when humor creation ability was measured using the CCT, it did not correlate with any of the four humor styles. A possible explanation for these different results with the two HCA measures may be that the creation of humorous cartoon captions, as measured by the CCT, is less relevant to the use of humor in everyday social interactions, as measured by the Humor Styles Questionnaire. In contrast, the FSHCT, which requires participants to generate humor while imagining telling a friend about an everyday frustrating situation, may be more strongly related to the ability to create humor in everyday social interactions, and therefore more strongly correlated with the HSQ. In any event, these findings suggest that humor creation ability may not be a unitary construct, and that different methods of assessing it may tap into somewhat different components of this ability.

A potential limitation of the FSHCT as used in this study is that participants were required to write out their responses instead of providing them orally. Allowing participants to respond orally might have resulted in a greater number of responses and perhaps a more valid assessment of their ability to produce humor in everyday social interactions. This is a question for future research.

Another important limitation of this study is the use of a correlational methodology, which precludes drawing inferences about the direction of causality among variables. For example, it is unclear whether using more adaptive (and less maladaptive) forms of humor causes enhanced psychological health and wellbeing, or whether having better mental health causes one to use humor in more beneficial ways (and if poorer health causes more maladaptive forms of humor use). Further research using experimental designs is needed to determine the direction of causality in the observed relationships between mental health and humor styles.

A further consideration is that humor creation ability was assessed in a laboratory setting. It is unknown whether people with higher scores on the FSHCT and the CCT actually use this ability in their daily lives. One potential method for examining this question in future research would be the use of experiential sampling techniques (Larson \& Csikszentmihalyi, 1983) which would permit participants to record actual instances (and the context) of humor creation as these attempts occur in everyday situations. It would be interesting to determine whether humor creation measures produce consistent results when collected in both a laboratory and real world setting.

Another limitation of this study is that the assessment of mental health variables relied exclusively on self-report questionnaires. This type of methodology is often subject to 
biases, such as the propensity for a participant to respond in socially desirable ways. As a result, desirable behaviors may be over-reported and unfavorable behaviors under-reported by those with a high need for approval. Future research should consider using peer ratings or physiological indicators of mental health (e.g., heart rate, skin conductance) to supplement self-report data.

In summary, the present findings provide additional evidence that the way humor is used is more important for well-being than is the ability to be funny. These findings have important implications for humor-based interventions. For example, our results suggest that such interventions should place less emphasis on training clients in the ability to generate humor, and more emphasis on examining the ways they use it in their daily lives, increasing their use of beneficial humor styles and decreasing their use of detrimental styles. In turn, experimental investigations of such humor-based interventions would be useful for determining the direction of causality in the associations between humor styles and psychological well-being.

\section{References}

Babad, E. Y. (1974). A multi-method approach to the assessment of humor: A critical look at humor tests. Journal of Personality, 42, 618-631.

Chen, G., \& Martin, R. A. (2007). A comparison of humor styles, coping humor, and mental health between Chinese and Canadian university students. Humor: International Journal of Humor Research, 20, 215-234.

Clabby, J. F. (1980). The wit: A personality analysis. Journal of Personality Assessment, 44, 307-310.

Diener, E., Emmons, R., Larsen, R., \& Griffin, S. (1985). The satisfaction with life scale. Journal of Personality Assessment, 49, 71-75.

Köhler, G., \& Ruch, W. (1996). Sources of variance in current sense of humor inventories: How much substance, how much method variance? Humor: International Journal of Humor Research, 9, 363-397.

Koppel, M. A., \& Sechrest, L. (1970). A multitrait-multimethod matrix analysis of sense of humor. Educational \& Psychological Measurement, 30, 77-85. 
Kuiper, N. A., Grimshaw, M., Leite, C., \& Kirsh, G. A. (2004). Humor is not always the best medicine: Specific components of sense of humor and psychological well-being. Humor: International Journal of Humor Research, 17, 135-168.

Larson, R., \& Csikszentmihalyi, M. (1983). The experience sampling method. New Directions for Methodology of Social and Behavioral Science, 15, 41-56.

Lazarus, R. S., \& Folkman, S. (1984). Stress, appraisal, and coping. New York: Springer.

Lefcourt, H. M., \& Martin, R. A., (1986). Humor and life stress: Antidote to adversity. New York: Springer-Verlag.

Lovibond, S.H., \& Lovibond, P.F. (1995). Manual for the Depression Anxiety Stress Scales (2nd Ed.) Sydney: Psychology Foundation.

Martin, R. A. (2007). The psychology of humor: An integrative approach. Burlington, MA: Elsevier Academic Press.

Martin, R. A. (2008). Humor and health. In V. Raskin (Ed.), The primer of humor research (pp. 479-522). Berlin: Mouton de Gruyter.

Martin, R. A., \& Lefcourt, H. M. (1983). Sense of humor as a moderator of the relation between stressors and moods. Journal of Personality \& Social Psychology, 45, 1313-1324.

Martin, R. A., \& Lefcourt, H. M. (1984). Situational Humor Response Questionnaire: Quantitative measure of sense of humor. Journal of Personality \& Social Psychology, 47, 145-155.

Martin, R. A., Puhlik-Doris, P., Larsen, G., Gray, J., Weir, K. (2003). Individual differences in uses of humor and their relation to psychological well-being: Development of the Humor Styles Questionnaire. Journal of Research in Personality, 37, 48-75.

Masten, A. S. (1986). Humor and competence in school-aged children. Child Development, 57, 461-473.

McGhee, P.E. (1999). Health, healing and the amuse system: Humor as survival training (3rd ed.). Dubuque, lowa: Kendall/Hunt.

Nieuwenhuijsen, K., de Boer, A. G., Verbeek, J. H., Blonk, R. W., \& van Dijk, F. J. (2003). The depression anxiety stress scales (DASS): Detecting anxiety disorder and depression in 
employees absent from work because of mental health problems. Occupational and Environmental Medicine, 60, 77-82.

O'Quin, K., \& Derks, P. (1997). Humor and creativity: A review of the empirical literature. In M. A. Runco (Ed.), The creativity handbook (Vol. 1, pp. 227-256). Cresskill, NJ: Hampton Press.

Rosenberg, M. (1965). Society and the adolescent self-image. Princeton, NJ: Princeton University Press.

Scheier, M., \& Carver, C. (1985). Optimism, coping, and health: Assessment and implications of generalized outcome expectancies. Health Psychology, 4, 219-247.

Scheier, M., Carver, C., \& Bridges, M. (1994). Distinguishing optimism from neuroticism (and trait anxiety, self-mastery, and self-esteem): A reevaluation of the Life Orientation Test. Journal of Personality and Social Psychology, 67, 1063-1078.

Shiner, R. L. (2006). Temperament and personality in childhood. In D. K. Mriczek \& T. D. Little (Eds.), Handbook of personality development (pp. 213-230). Mahway, NJ: Lawrence Erlbaum Associates.

Silbert, E., \& Tippett, J. (1965). Self-esteem: Clinical assessment and measurement validation. Psychological Reports, 16, 1017-1071.

Sveback, S. (1974). Revised questionnaire on the sense of humor. Scandinavian Journal of Psychology, 15, 328-331.

The New Yorker. (2008). Cartoon caption contest (previous winners). Retrieved November 25, 2008, from http://www.newyorker.com/humor/caption/.

Turner, R. G. (1980). Self-monitoring and humor production. Journal of Personality, 48, 163172.

About the authors:

Kim R. Edwards is currently a Ph.D. candidate in clinical psychology at the University of Western Ontario under the supervision of Rod A. Martin. Her research interests include humor, health, and positive psychology. 
Address for correspondence: K. R. Edwards, Department of Psychology, Westminster Hall, University of Western Ontario, London, Ontario, Canada, N6A 3K7

E-mail: kedward7@uwo.ca

Rod A. Martin is a professor of clinical psychology at the University of Western Ontario. His research focuses on the conceptualization and measurement of sense of humor, and on the association between humor and psychosocial well-being. 